Brit. J. industr. Med., 1950, 7, 76.

\title{
NOTES ON THE TOXICOLOGY OF COBALT METAL
}

\author{
BY \\ H. E. HARDING
}

From the Department of Pathology, Sheffield University

This investigation originated in a report by Dr. Joan Cotterill, one of H.M. medical inspectors of factories, that workers in a Midlands factory making hard cutting tools complained of shortness of breath and that in radiographs of their lungs, some of them showed abnormal shadows. Many of the processes in the factory are trade secrets, but it is known that powdered cobalt metal is used as a bonding material in the manufacture of hard cutting tools containing tungsten carbide and other substances.

Samples of metallic cobalt, metallic tungsten and tungsten carbide were obtained from the factory, but it is possible that other powders are also used in the process of making the tools. Sterile 5 per cent. suspensions in physiological saline of each of these powders were injected into the tracheæ of young piebald rats under ether anæsthesia: the suspensions of metallic tungsten and of tungsten carbide produced no unexpected results and are not further considered here.

\section{Preliminary Investigations}

All the six rats injected with metallic cobalt died within a few hours, and at necropsy their lungs were hæmorrhagic and very œdematous. Repetition of the experiment with a freshly prepared suspension gave a similar result. Two adult rats were given $2 \mathrm{ml}$. of a 5 per cent. sterile suspension intraperitoneally : one died within 15 minutes, but this animal had two chronic abscesses in its liver and cannot be regarded as normal. The other animal became lethargic within 20 minutes, recovered considerably, but was found dead 45 hours later. There was hæmorrhage into the lungs : most of the injected metal was enclosed in the omentum or against the pelvic colon. Two adult rats given intraperitoneally $5 \mathrm{ml}$. of the supernatant fluid after centrifuging the saline suspension looked slightly unhappy for a short time but recovered completely within an hour. No cobalt was detectable in $10 \mathrm{ml}$. of the saline by the chemical methods available to us at this time. Since these results were quite unexpected, a sample of spectroscopically pure cobalt powder was obtained from a different source. Intratracheal injections of $1 \mathrm{ml}$. of a 5 per cent. sterile suspension in saline proved rapidly fatal to rats. Dr. Cotterill was then asked to enquire whether there were complaints of acute respiratory symptoms in the works, and she found that no such complaints had been made. It seemed, therefore, that no practical approach could be made by this method to the investigation of a possible chronic effect of cobalt metal on the lungs, and further investigation of the acute reactions had to be deferred for some time.

\section{Experimental Results}

Rats under light ether anæsthesia were given intratracheal injections of approximately $1 \mathrm{ml}$. of a 5 per cent. sterile suspension of metallic cobalt in physiological saline. Instead of recovering very rapidly from the anæsthetic these animals appeared to become more deeply anæsthetized and to come round only slowly. They then passed insensibly, and at varying rates, into a condition closely resembling the shock state. They were lethargic, had difficulty in righting themselves when placed on their backs, showed rapid respiration, which in some animals became periodic, and their body temperature fell considerably. All the animals died within periods varying from 15 minutes to six hours. At necropsy the lungs were grossly œdematous and showed many small hæmorrhages. These changes in the lungs were confirmed histologically, and in the sections some cobalt metal was visible within the bronchi and atria, and close to the alveolar walls near the ends of the bronchi.

Six adult rats given $2 \mathrm{ml}$. of a similar suspension intraperitoneally were at first unusually active, and gave the impression that the injection was irritant. After an hour one of the rats had some difficulty in walking ; the rest appeared normal. After a further hour, two animals were very lethargic, had difficulty in walking, were cold and breathing rapidly; the others were very quiet but not obviously unwell. Five hours after the injection one animal was very 
unwell, cold, breathing rapidly, and usually unable to right itself if placed on its back. Four animals were notably lethargic and one was quite lively. The animal which was the worst affected was killed at this time. Its lungs were congested and its heart dilated ; the peritoneal cavity contained some $5 \mathrm{ml}$. of clear fluid. Next day three rats sat hunched up, were lethargic, rather cold, and were breathing too rapidly. The other two appeared fairly normal but none of them was seen to eat food. On the second day following injection the rats appeared to have recovered almost completely, and were killed. All showed a considerable quantity of slightly pink fluid in the peritoneal cavity. Judged by the naked eye, all, or almost all, of the metal powder was still present and caught up either in the omentum or alongside the pelvic colon.

Six rats, three months old, were exposed for six hours to a high concentration of cobalt dust in a slightly modified form of the chamber described by Lloyd Davies (1946). The concentration of dust particles was similar to that of other dusts to which animals had been exposed daily for several months. Rats exposed in this chamber usually huddle together and sleep most of the time, but these animals were unusually active during the first half of their exposure ; they were also noted frequently to rub their noses with their paws. None of them looked unfit when taken out of the chamber, but two died overnight and one was killed when moribund the next morning. All these animals showed extremely hæmorrhagic lungs with much œdema. Two of the remaining animals seemed normal but the third was cold and inactive and showed forcible, almost gasping, respiration. These last three animals were found dead on the second morning. Their lungs, which appeared similar to those of the previous animals, were dried, ashed, and examined chemically.

Six further rats were given a similar exposure. Two were killed immediately after coming out of the chamber, two 18 hours later, and two 24 hours later. The last four looked unfit, but were not obviously moribund. All of these animals showed considerable œdema of the lungs with multiple tiny hæmorrhages.

That this effect of inhaling cobalt dust was not peculiar to rats was shown by exposing at various times two golden hamsters, two adult cavies, two rabbits, and six mice. All showed the same kind of reaction and all died or were killed when moribund. The hamsters tolerated the dust much better than the other animals, but both of them were killed when evidently unwell after exposure for six hours on four consecutive days. The hamsters' lungs were congested and œdematous, and showed considerable desquamation of the bronchial epithelium. All the other animals showed gross œdema and numerous hæmorrhages in the lungs. The œdema fluid contained considerable amounts of protein.

\section{Chemical Investigations}

Physiological saline autoclaved with a large quantity of cobalt powder, kept for several days at $37^{\circ} \mathrm{C}$., and then filtered and centrifuged, dissolved $0.03 \mathrm{mg}$. of cobalt per $100 \mathrm{ml}$. To reconstituted human plasma a large excess of cobalt powder was added and the mixture kept at $37^{\circ} \mathrm{C}$., with frequent shaking, for 24 hours. It was then filtered and centrifuged; the supernatant fluid contained 15.25 mg. cobalt per $100 \mathrm{ml}$. A similar figure was obtained after Seitz filtration. No difference was detected between rats who were given $10 \mathrm{ml}$. of this cobaltic plasma intraperitoneally and those given a similar amount of normal human plasma. The blood serum of a rabbit, killed when moribund at the end of its second day of exposure to dust, contained $0.26 \mathrm{mg}$. cobalt per $100 \mathrm{ml}$. Serum from a normal rabbit had no detectable cobalt in $5 \mathrm{ml}$. The grouped lungs of three rats that died two days after six hours' exposure to dust, contained 0.13 mg. cobalt. Judging from sections of other animals, some of this may still have been in particulate form.

\section{Discussion}

These investigations arose from a suspicion that metallic cobalt dust might be responsible for chronic damage to the lungs of workers in a particular factory. After the preliminary investigations had been completed the papers of Fairhall and his associates $(1947$; 1949) became available. They also suggested that cobalt dust might well be responsible for the excessive incidence of respiratory disease, and possibly for some granular or conglomerate markings in the radiographs of the lungs of workers in the cemented tungsten carbide industry. The investigations recorded here do not answer this question, since on the experimental animals only acute, and usually lethal, effects could be obtained, while there is no evidence of any acute respiratory irritation in industrial workers.

From these experiments it is evident that metallic cobalt powder has an acute irritant action, and leads to severe alterations in capillaries in the lungs or peritoneum with the outpouring of a considerable quantity of fluid and sometimes with actual hæmorrhages. The production of a shocklike state was at one time thought to be possibly connected with interference with the enzyme systems associated with the breakdown and synthesis of adenosine triphosphate (Green and Stoner, 
1950), but obviously the simpler explanation is the right one and the condition is in fact oligæmic shock from fluid loss.

Because of the very low solubility of cobalt metal in saline, it was thought that the effects might be due to some extremely toxic impurity, but this was disproved by finding exactly similar reactions to a sample known to be chemically pure. It appears very unlikely that cobalt could produce such a severe effect without going into solution, and in this respect it is noteworthy that its solubility in plasma is some 500 times greater than in saline. The effect is, however, largely a local one although this may produce more general secondary effects. The clinical condition following injection or inhalation of cobalt metal differs from that described as produced by poisoning with soluble cobaltic salts (Hendrych and Weden, 1934) and it appears improbable that sufficient cobalt was absorbed under the conditions of these experiments to produce a general toxic reaction. It is to be noted that a fairly large $(10 \mathrm{ml}$.) intraperitoneal dose of plasma saturated with cobalt was without evident effect on the rat.

The toxic dose of cobalt by mouth or by injection of soluble salts is relatively high (Chittenden and Norris, 1889; Hendrych and Weden, 1934). Frederick and Bradley (1946) found the $\mathrm{LD}_{50}$ of cobalt metal powder to be $10-20 \mathrm{mg}$. per $100 \mathrm{~g}$. bodyweight following intraperitoneal injection in white rats. In our experiments intraperitoneal injections of 50-100 mg. into rats of approximately $180 \mathrm{~g}$. bodyweight were frequently, but not invariably, fatal. Most of the injected metal was, however, still present in that form both in animals that died and in those that recovered. After some hours the cobalt was enclosed within the omentum or peritoneum and appeared to exert no further action. It is therefore impossible to give any real lethal dose, but this is presumed to be small if the particle size is small.

Again, it is not possible to give any accurate lethal dose when the metal reaches the lungs either by injection into the trachea or by inhalation. Following injections, and to a less extent following inhalation, there is unchanged metal within the air passages or lungs. Those animals that inhaled cobalt, also swallowed unmeasured amounts. Although absorption from the gut is believed to be very slight (Kent and McCance, 1941), it is possible that some reached the blood stream from this source.

On the whole, then, it seems probable that the local effect on capillaries results from the solubility of cobalt in tissue fluids such as plasma, and that the damage is done during the process of solution, which presumably involves some attachment of cobalt metal to protein.

\section{Summary}

Cobalt metal powder suspended in saline or in air produces severe acute damage to capillaries. In the lungs of experimental animals it leads to severe, usually fatal, œdema and hæmorrhage. In the peritoneal cavity it leads to ascites and oligæmic shock that may prove fatal. This action of cobalt is related to its solubility in protein-containing fluids. It is 500 times more soluble in plasma than in saline.

Dr. Joan Cotterill supplied information about the workers, obtained samples of the powders used, and was responsible for the initiation of these experiments. A sample of spectroscopically pure cobalt was given by Messrs. W. Jessup of Sheffield. The chemical estimations were made by Mr. J. W. Westrop, B.Sc. The expenses of this investigation were met by a grant from the Medical Research Fund of Sheffield University.

\section{REFERENCES}

Chittenden, R. H., and Norris, C. (1889). Stud. Lab. Physiol. Chem., Yale Univ., 3, 148 (quoted by Fairhall, L. T., and others)

Fairhall, L. T., Castberg, H. T., Carrozzo, N. J., and Brinton, H. P. (1947)." Occup. Med., 4, 371.

-C, Keenan, R. G., and Brinton, H. P. (1949). Publ. Hlth. Rep., Wash., 64, 485.

Frederick, W. G., and Bradley, W. R. (1946). Report of Eighth Annual Meeting of the American Industrial Hygiene Association, Chicago (quoted by Fairhall, L. T., and others).

Green, $\mathrm{H}$. N., and Stoner, H. B. (1950). "The Biological Action of the Adenine Nucleotides'. Lewis, London.

Hendrych, F., and Weden, H. (1934). In Hefftner, A., and Heubner, W., "Handbuch der experimentellen Pharmakologie ", Berlin, 3 , ii, 1401 .

Kent, N. L., and McCance, R. A. (1941). Biochem. J., 35, 877. Lloyd Davies, T. A. (1946). British Journal of Industrial Medicine, 